\title{
Gossypol Promotes Degeneration of Ovarian Follicles in Rats
}

\author{
Ivana Cristina Nunes Gadelha, ${ }^{1}$ Michelly Fernandes de Macedo, ${ }^{1}$ \\ Sílvia Catarina Salgado Oloris, ${ }^{2}$ Marilia Martins Melo, ${ }^{3}$ and Benito Soto-Blanco ${ }^{3}$ \\ ${ }^{1}$ Programa de Pós-graduação em Ciência Animal, Universidade Federal Rural do Semiárido, BR 110 Km 47, \\ 59628-360 Mossoró, RN, Brazil \\ ${ }^{2}$ Fundação Ezequiel Dias (FUNED), Rua Conde Pereira Carneiro 80, 30510-010 Belo Horizonte, MG, Brazil \\ ${ }^{3}$ Departamento de Clínica e Cirurgia Veterinárias, Escola de Veterinária, Universidade Federal de Minas Gerais, \\ Av. Antônio Carlos 6627, 30123-970 Belo Horizonte, MG, Brazil \\ Correspondence should be addressed to Benito Soto-Blanco; bsotoblanco@yahoo.com.br
}

Received 28 April 2014; Accepted 15 July 2014; Published 23 July 2014

Academic Editor: Elisabetta Baldi

Copyright (C) 2014 Ivana Cristina Nunes Gadelha et al. This is an open access article distributed under the Creative Commons Attribution License, which permits unrestricted use, distribution, and reproduction in any medium, provided the original work is properly cited.

\begin{abstract}
The present study aimed to determine if gossypol interferes with ovarian follicles in rats. Twenty-four female Wistar rats were assigned to two equal groups: one control group and the other dosed with gossypol ( $25 \mathrm{mg} / \mathrm{kg} / \mathrm{day}$, subcutaneously) for 15 days. Ovarian follicles were histologically classified according to the stage of development and as normal or atretic. Gossypol treatment reduced the length of estrous with an increase in the duration of the diestrus phase. This compound was responsible for reduced serum levels of T4 and progesterone. Treatment with gossypol was responsible for a significant reduction in the number of normal ovarian follicles and a significant increase in the number of atretic follicles, both in all stages of development. Thus, treatment of rats with gossypol was responsible for reduction in the number of viable follicles and changes in hormone levels that resulted in interference of the estrous cycle.
\end{abstract}

\section{Introduction}

Gossypol (2,2-bi(8-formyl-1,6,7-trihydroxy-5-isopropyl-3methylnaphthalene)) is a polyphenolic compound produced by pigment glands in roots, stems, leaves, seeds, and flower buds of cotton (Gossypium spp). The function of this compound is to deter various insects from feeding on the plant $[1,2]$. Signs of gossypol toxicosis include decreased growth rate, anorexia, labored breathing, and dyspnea [2]. Other effects include damage to hepatocytes $[3,4]$ and lymphocyte cytotoxicity leading to immunodeficiency [5-7].

The male reproductive toxicity of gossypol has been reported in many studies [8]. Gossypol inhibits spermatogenesis by decreasing the sperm count and spermatozoid motility and viability. The male infertility effect is caused by impaired sperm motility, decreased sperm concentrations, and specific mitochondrial injury to the sperm tail and damage to the germinal epithelium [9-12]. The gossypol-mediated spermatozoid disturbance mechanism includes inhibition of the release and utilization of ATP by sperm cells [13]. Furthermore, gossypol inhibits calcium influx and Mg-ATPase and $\mathrm{Ca}-\mathrm{Mg}$-ATPase activity in spermatozoid plasmatic membranes [14]. Abnormal spermatozoids are produced because gossypol produces ultrastructural alterations in the nuclear membrane, endoplasmic reticulum, and mitochondria $[15,16]$. In cultured Sertoli cells from pigs, gossypol also decreased cellular oxidase activity and DNA damage [17]. Reduced nuclear expression of androgen receptors was observed in Leydig cells, Sertoli cells, and myoid cells from rats fed gossypol-rich cottonseed flour [18]. However, such effects are reversible after the cessation of gossypol exposure [19].

Even though gossypol has well-known toxic effects in the male reproductive system, there are few studies on its effects on female reproduction. Female exposure to gossypol has been associated with interference of the estrous cycle, 
pregnancy, and early embryonic development [1,2]. Gossypol has been shown to affect rodent estrous cycles $[20,21]$ and pig granulosa cell function [22]. Gossypol affected ovarian steroidogenesis in vitro $[23,24]$ as well as bovine oocyte cumulus expansion and nuclear maturation [24]. The present study aimed to determine whether gossypol interferes with the ovarian folliculogenesis in rats. Our work also proposes a model for determining the effects of toxic substances on ovarian metabolism by ovarian follicle classification and quantification.

\section{Material and Methods}

2.1. Animals. Female Wistar rats, 60 to 70 days old, weighing approximately $120 \mathrm{~g}$ each, from the Animal Sciences Department, UFERSA, Mossoró, RN, Brazil, were used. During the entire study period, the rats were housed in plastic cages under controlled environmental conditions with a $12 \mathrm{~h}$ light/dark cycle and at a temperature of $24 \pm 3^{\circ} \mathrm{C}$. Regular rodent chow (Labina, Purina, São Lourenço da Mata, PE, Brazil) and tap water were provided ad libitum. Animal studies have been approved by the Institutional Animal Care and Use Committee at the Universidade Federal Rural do Semi-Árido/UFERSA (process number 23091.000690/201272 ) and have been performed in accordance with the ethical standards laid down in the 1964 Declaration of Helsinki and its later amendments.

2.2. Experimental Design. The estrous cycle of the rats was monitored twice a day by vaginal smear for seven consecutive days; only rats that exhibited regular estrous cycles were used in the experiment. Twenty-four female rats were randomly and equally distributed into two groups: a control group (injected with saline solution subcutaneously) and a group dosed with gossypol ( $25 \mathrm{mg} / \mathrm{kg} /$ day subcutaneously) for 15 consecutive days. Rats were dosed with $(+/-)$ gossypol acetic acid (Fluka, G4382) with purity about $95 \%$.

Vaginal smears were carried out on each animal every day between 7:00 and 9:00 a.m. and again between 5:00 and 6:00 p.m. The smears were collected by lavage with $20 \mu \mathrm{L}$ of $0.9 \% \mathrm{NaCl}$ solution, spotted thinly on a microscope slide, and evaluated under a light microscope. The cell counts and morphology were used for the determination of the estrous cycle phases, characterized as proestrus, estrus, metestrus, and diestrus [25].

On the day after the last dosing, all rats were deeply anesthetized by intraperitoneal injection of xylazine $(5 \mathrm{mg} / \mathrm{kg})$ and ketamine $(60 \mathrm{mg} / \mathrm{kg})$ to collect the ovaries, uterus, thyroid glands, and blood samples from the vena cava. Formalinfixed, paraffin-embedded tissue samples were sliced into $5 \mu \mathrm{m}$ thick sections and stained with hematoxylin and eosin (H\&E) for histological analysis.

2.3. Hormonal Analysis. Frozen sera were used for the determination of the serum levels of estradiol, progesterone, luteinizing hormone ( $\mathrm{LH}$ ), thyroxine (T4), triiodothyronine (T3), and thyroid stimulating hormone (TSH). Hormone levels were analyzed by an ELISA automated analyzer (Elisys
Uno, Human, Wiesbaden, Germany) with specific kits (RPC Diagnostic Systems, Nizhny Novgorod, Russia).

2.4. Morphological Analysis of the Ovarian Follicles. The ovaries from all rats were collected and fixed in $10 \%$ buffered formalin. Five-micron thick paraffin-embedded sections were collected at $60 \mu \mathrm{m}$ intervals throughout the tissue and stained with $\mathrm{H} \& \mathrm{E}$. Histological analysis, including qualitative and quantitative assessment of ovarian follicles, was performed. Follicles were classified according to the stage of development as primordial, primary, secondary, or antral [26]. Primordial follicles were defined as those with one layer of flattened granulosa cells, primary follicles presented one layer of cuboidal granulosa cells, secondary follicles presented two layers of cuboidal granulosa cells, and antral follicles presented the antral cavity (Figure 1).

Follicles were also classified as normal or atretic. Normal follicles presented a regular shape and well-organized granulosa cells, without signs of atresia. Atretic follicles were characterized by retracted oocytes, a pyknotic nucleus, discontinued basement membrane, and disorganized granulosa cells $[27,28]$.

2.5. Statistical Analysis. The obtained data were statistically analyzed using R software (version 3.0.0). Data normality was evaluated using a Shapiro-Wilk test and the homogeneity of variance was evaluated using an $F$ test. Welch's $t$-test was employed and $P$ values $<0.05$ were considered statistically significant.

\section{Results}

No clinical signs of poisoning were observed in any of the rats. There was no significant difference in body weight between the groups on the first and last days of the experiment, but body weight gain was significantly $(P<0.05)$ reduced in rats dosed with gossypol (Table 1). Furthermore, the treatment with gossypol significantly $(P<0.05)$ increased the length of the diestrus stage (Table 1 ).

At necropsy, hydrometra was observed in five of the rats dosed with gossypol and in one rat from the control group. No histological lesions were found in the thyroid glands or the uterus from any of the rats.

Our results also verified that gossypol was responsible for hormonal interference, characterized by significantly $(P<$ 0.05 ) reduced serum levels of T4 and progesterone and a significantly $(P<0.05)$ increased T3/T4 ratio (Table 2 ). Conversely, gossypol treatment did not affect the serum levels of T3, TSH, LH, and estradiol.

Additionally, treatment with gossypol was responsible for a significant $(P<0.05)$ reduction in the number of normal ovarian follicles and a significant $(P<0.05)$ increase in the number of atretic follicles, both in all stages of development (Table 3 and Figure 2). On average, the ovaries of female rats in the control group had $83.3 \%$ normal follicles and $16.7 \%$ atretic follicles, whereas rats treated with gossypol had normal and atretic follicle incidence rates of $36.6 \%$ and $63.4 \%$, respectively. 


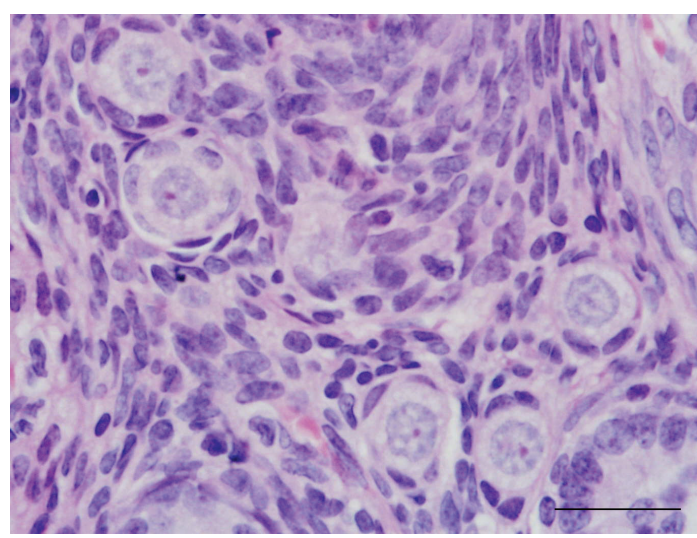

(a)

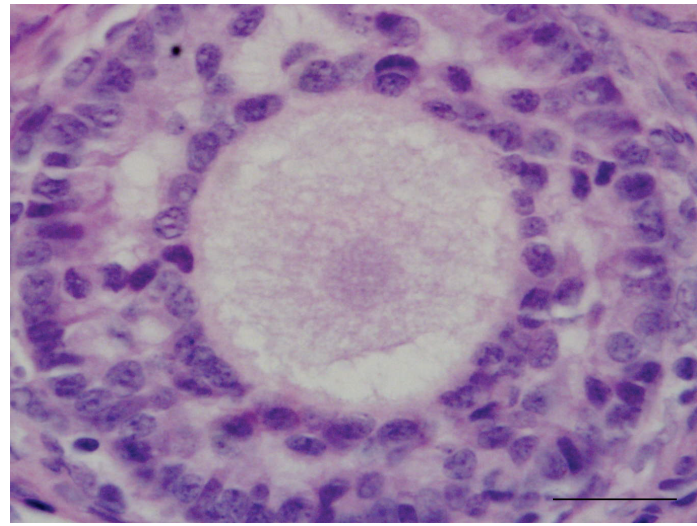

(c)

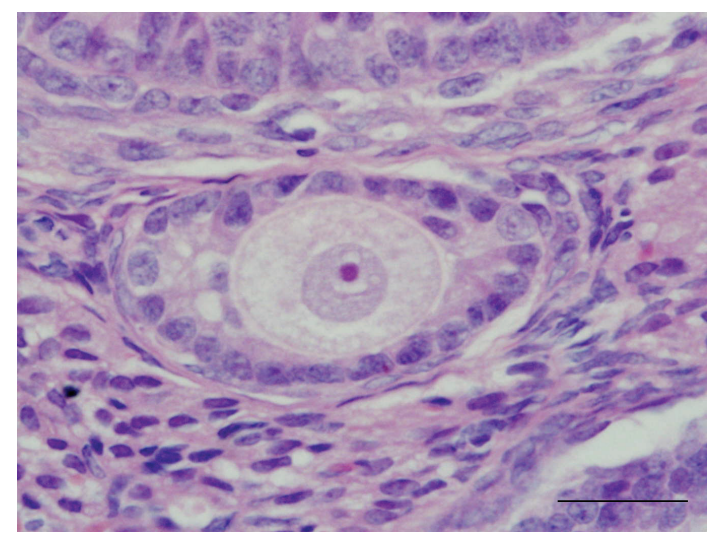

(b)

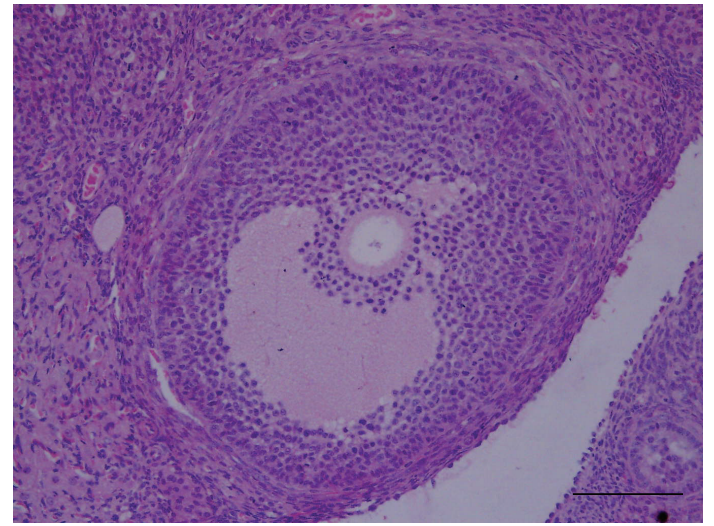

(d)

FIGURE 1: Ovaries from control rats showing normal (a) primordial, (b) primary, (c) secondary (H\&E, bar $=25 \mu \mathrm{m}$ ), and (d) antral follicles $(\mathrm{H} \& \mathrm{E}$, bar $=100 \mu \mathrm{m})$.

TABLE 1: Body weight, body weight gain (in grams), and length (in hours) of the estrous cycle phases of female rats dosed with gossypol $(25 \mathrm{mg} / \mathrm{kg} /$ day) or $0.9 \%$ saline (control group) subcutaneously for 15 consecutive days.

\begin{tabular}{lccc}
\hline & Control $(n=12)$ & Gossypol $(n=12)$ & \\
\hline Body weight $(\mathrm{g})$ & & & \\
$\quad$ Day 0 & $190.4 \pm 4.32$ & $192.2 \pm 7.62$ & n.s. \\
$\quad$ Day 15 & $197.5 \pm 2.91$ & $186.7 \pm 6.15$ & n.s. \\
Body weight gain (g) & $7.08 \pm 2.07$ & $-5.58 \pm 2.43$ & 0.0006792 \\
Diestrus (h) & $44.0 \pm 1.71$ & $51.0 \pm 2.15$ & 0.01875 \\
Metestrus (h) & $1.00 \pm 0.67$ & $3.50 \pm 1.73$ & n.s. \\
Estrus (h) & $24.5 \pm 1.88$ & $20.0 \pm 1.71$ & n.s. \\
Proestrus (h) & $26.5 \pm 1.16$ & $21.5 \pm 2.39$ & n.s. \\
\hline
\end{tabular}

${ }^{1}$ Welch's $t$ test.

n.s.: not significant $(P>0.05)$.

\section{Discussion}

We found that gossypol treatment resulted in increase in the length of the diestrus and metestrus stages (about $116 \%$ and $350 \%$ of controls, resp.) and reduction in the length of the proestrus and estrus stages (both about $81 \%$ of controls). Interferences on estrous cycle were observed by others [20, 21]. The administration of $20 \mathrm{mg} / \mathrm{kg}$ of gossypol acetic acid orally for 60 days [20] and of $25 \mathrm{mg} / \mathrm{kg}$ gossypol acetic acid via intramuscular injection for 3 to 5 days [21] caused prolonged and irregular estrous cycles in rats. Female rats dosed with $60 \mathrm{mg} / \mathrm{kg}$ gossypol acetic acid for 30 days showed a reduced number of estrus cycles, which did not occur when they were dosed with $40 \mathrm{mg} / \mathrm{kg}$ [29]. Similarly to our study, the percentage of animals in diestrus was increased in rats dosed with 5 or $10 \mathrm{mg}$ gossypol/ $\mathrm{kg} /$ day subcutaneously for 20 days 
TABLE 2: Serum concentrations of estradiol, progesterone, luteinizing hormone (LH), thyroxine (T4), triiodothyronine (T3), and thyroid stimulating hormone (TSH) in female rats dosed with gossypol $(25 \mathrm{mg} / \mathrm{kg} / \mathrm{day}$ ) or $0.9 \%$ saline (control group) subcutaneously for 15 consecutive days.

\begin{tabular}{lccc}
\hline & Control $(n=12)$ & Gossypol $(n=12)$ & $P$ value \\
\hline T4 $(\mathrm{ng} / \mathrm{dL})$ & $2.21 \pm 0.10$ & $1.80 \pm 0.12$ & 0.01446 \\
T3 $(\mathrm{pg} / \mathrm{mL})$ & $5.68 \pm 0.41$ & $7.73 \pm 1.07$ & n.s. \\
T3/T4 ratio & $2.62 \pm 0.19$ & $4.62 \pm 0.77$ & 0.02635 \\
TSH $(\mu \mathrm{IU} / \mathrm{mL})$ & $4.00 \pm 1.76$ & $3.91 \pm 1.75$ & n.s. \\
Progesterone $(\mathrm{ng} / \mathrm{mL})$ & $48.3 \pm 7.61$ & $24.5 \pm 4.16$ & 0.01317 \\
LH $(\mathrm{mIU} / \mathrm{mL})$ & $0.22 \pm 0.04$ & $0.21 \pm 0.04$ & n.s. \\
Estradiol $(\mathrm{pg} / \mathrm{mL})$ & $10.7 \pm 3.83$ & $16.7 \pm 4.53$ & n.s. \\
\hline
\end{tabular}

${ }^{1}$ Welch's $t$ test.

n.s.: not significant $(P>0.05)$.

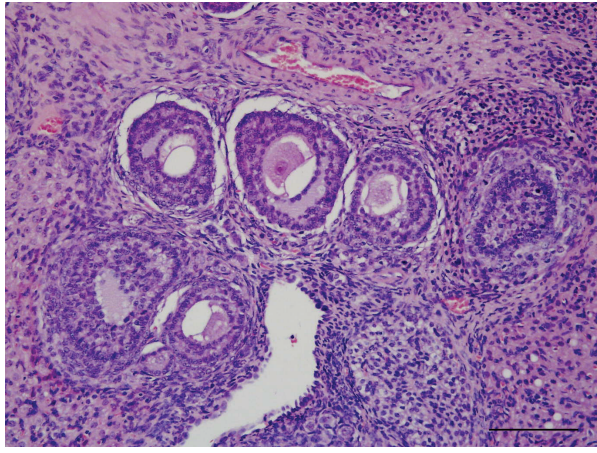

(a)

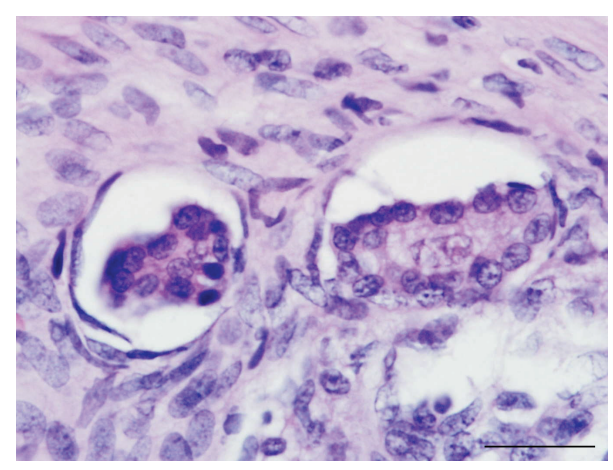

(b)

Figure 2: (a) Ovaries from gossypol treated rats showing atretic primordial, primary, and secondary follicles (H\&E, bar $=100 \mu \mathrm{m})$. (b) Atretic primordial and primary follicles from a gossypol-dosed rat $(\mathrm{H} \& \mathrm{E}$, bar $=25 \mu \mathrm{m})$.

[30]. Conversely, gossypol treatment has been shown to have no effect on ovulation in rats [31] and did not alter estrous cycles in hamsters [32].

Our results verified that gossypol is responsible for hormonal interference, as evidenced by reduced serum levels of progesterone and T4 and an increased T3/T4 ratio. Reduced serum levels of progesterone were reported in female rats that received $25 \mathrm{mg} / \mathrm{kg}$ gossypol acetic acid via intramuscular injection for 3 to 5 days [21] and in pregnant rats dosed orally with 60,90 , and $120 \mathrm{mg} / \mathrm{kg} /$ day gossypol acetic acid for the first 10 days after coitus [33]. Data from the in vitro studies indicate that gossypol inhibited the basal and stimulated progesterone secretion levels in luteal cells $[23,34]$, granulosa cells from small follicles [35], and oocyte-cumulus complexes isolated from large antral porcine follicles [36]. Several mechanisms may be involved in the inhibition of progesterone synthesis, including the inhibition of adenylate cyclase [23, 34] and $3 \beta$-hydroxysteroid dehydrogenase [37], as well as by nitric oxide generation [35]. Thus, the interference of ovarian steroidogenesis may be the mechanism by which gossypol affects the estrous cycle.

Gossypol is also an antithyroidal compound [38, 39]. Rats from the present study showed reduced serum levels of free T4 and had an increased T3/T4 ratio. Earlier studies with male [38] and female [39] rats showed decreased blood levels of free T4 and T3 levels after dosing with gossypol acetic acid.
Moreover, the histopathological evaluation of thyroid glands from male rats revealed follicular degeneration and atrophy [38], but no histological alteration was observed in thyroid glands in our study. Reduced T3 levels were also observed in rabbits, but this reduction was reverted when dosing was discontinued [10]. However, gossypol dosing resulted in increased T3 serum levels without affecting T4 in rats [40] and sheep [41]. The thyrotropic cells in the pituitary gland, which specializes in TSH synthesis and secretion, showed hypertrophy, hyperplasia, and degranulation after gossypol acetate dosing in rats [42]. This finding differs from our results, which indicated that TSH levels were not affected by gossypol treatment. Although these findings are conflicting, there is a general consensus that gossypol affects thyroid gland metabolism, but the mechanism is uncertain.

The treatment with gossypol was also responsible for both a significant reduction in the number of normal follicles and a significant increase in the number of atretic follicles in all stages of development. On average, the ovaries of the rats in the control group had $83.3 \%$ normal follicles and $16.7 \%$ atretic follicles, whereas the rats treated with gossypol had $36.6 \%$ normal follicles and $63.4 \%$ atretic follicles. All types of normal follicle cell types are reduced about a third and the atretic follicle cell types are increased about three times. The ovarian weight was decreased in rats dosed with 5 or $10 \mathrm{mg}$ gossypol/kg/day subcutaneously for 20 days [30]. 
TABLE 3: Ovarian follicle populations in female rats dosed with gossypol ( $25 \mathrm{mg} / \mathrm{kg} /$ day) or $0.9 \%$ saline (control group) subcutaneously for 15 consecutive days.

\begin{tabular}{|c|c|c|c|}
\hline Follicles & Control $(n=12)$ & Gossypol $(n=12)$ & $P$ value $^{1}$ \\
\hline \multicolumn{4}{|c|}{ Number of normal follicles } \\
\hline Primordial & $341.8 \pm 25.6$ & $122.6 \pm 20.1$ & $<0.0001$ \\
\hline Primary & $115.5 \pm 14.8$ & $49.0 \pm 5.03$ & 0.0008635 \\
\hline Secondary & $62.6 \pm 11.3$ & $20.1 \pm 4.54$ & 0.003426 \\
\hline Antral & $55.8 \pm 6.52$ & $14.5 \pm 3.71$ & $<0.0001$ \\
\hline Total & $575.6 \pm 51.8$ & $206.2 \pm 27.9$ & $<0.0001$ \\
\hline \multicolumn{4}{|c|}{ Number of atretic follicles } \\
\hline Primordial & $66.3 \pm 10.7$ & $168.3 \pm 24.1$ & 0.001489 \\
\hline Primary & $22.5 \pm 2.32$ & $65.8 \pm 6.99$ & $<0.0001$ \\
\hline Secondary & $22.2 \pm 4.26$ & $71.7 \pm 9.44$ & 0.00023 \\
\hline Antral & $8.08 \pm 1.52$ & $39.6 \pm 3.95$ & $<0.0001$ \\
\hline Total & $119.1 \pm 12.8$ & $345.4 \pm 32.8$ & $<0.0001$ \\
\hline \multicolumn{4}{|c|}{ Proportion of follicles (in \%) } \\
\hline Normal & $82.1 \pm 2.05$ & $36.6 \pm 1.73$ & $<0.0001$ \\
\hline Atretic & $17.8 \pm 2.05$ & $63.4 \pm 1.73$ & $<0.0001$ \\
\hline \multicolumn{4}{|c|}{ Number of total follicles } \\
\hline Total & $694.7 \pm 54.5$ & $551.6 \pm 57.2$ & n.s. \\
\hline
\end{tabular}

${ }^{1}$ Welch's $t$ test.

n.s.: not significant $(P>0.05)$.

Conversely, no pathological lesions were found in the ovaries of female rats dosed with 40 or $60 \mathrm{mg} / \mathrm{kg}$ gossypol acetic acid for 30 days [29]. However, in both studies [29, 30] the ovarian follicles were not classified not counted. Thus, the classification and counting of ovarian follicles used in our study may be a useful tool for studying compounds that potentially affect female gametogenesis.

In female mammals, the number of ovarian primordial follicles is fixed at the time of birth. The primordial follicles grow into primary, secondary, and antral follicles in a continuous and nonreversible process. The damage to primary, secondary, and antral follicles may lead to temporary infertility when the primordial follicles are not affected. On the other hand, the injury to primordial follicles may result in permanent infertility because of the eventual depletion of the pool of these follicles [43]. Therefore, it is feasible to speculate that gossypol exposure may reduce the ovarian reserve of follicles, impairing female fertility. However, gossypol seems to not be a potential drug to promote female castration because of its toxicity, which in our study was evidenced by body weight loss.

It was observed that gossypol inhibited steroidogenic activity and redox status and stimulated the vascular endothelial growth factor production in an in vitro experiment with porcine granulosa cells [22]. Furthermore, gossypol showed cytotoxic and apoptotic activity in ovarian carcinoma cell lines $[44,45]$. Due to increased follicular atresia, the folliculogenesis could be severely degraded by the action of this compound, dramatically reducing the conception rate of exposed females. In fact, female rats that received $20 \mathrm{mg} / \mathrm{kg} / \mathrm{day}$ of gossypol acetic acid for 60 days presented delayed mating and a reduced rate of pregnancy and number of viable embryos when compared to controls [20]. Additionally, it is likely that exposed females will experience early reproductive senescence.

An additional interesting observation made at necropsy was the occurrence of hydrometra in five rats from the gossypol treated group and one rat from the control group. High incidence of infertility and atrophy of the uterus was observed in women exposed to gossypol through the ingestion of cottonseed oil in China [8]. Thus, the increased frequency of hydrometra must be one of the effects of gossypol, which likely contributes to the infertility of females exposed through the ingestion of cotton seed.

In conclusion, treatment with gossypol was responsible for interference of the estrous cycle in the rats. This interference involved a reduction in the number of viable follicles as well as hormonal changes, which might negatively impact female reproduction. The overall results from the present study show the relevance of ovarian follicle classification and quantification in the determination of estrous cycling. This is pertinent for future studies that aim to determine the effects of toxic substances on ovarian metabolism.

\section{Conflict of Interests}

The authors declared no potential conflict of interests with respect to the research, authorship, and/or publication of this paper.

\section{Acknowledgments}

Michelly Fernandes de Macedo was supported by postdoctoral fellowship from CAPES-PNPD (project no. 23038.00$7325 / 2011-52$ ). This research has been supported by the grant 
of the CNPq (project no. 474432/2012-2) and support for language editing of the Pró-Reitoria de Pesquisa of the Universidade Federal de Minas Gerais (Edital PRP-UFMG 03/ 2013).

\section{References}

[1] I. C. N. Gadelha, A. H. N. Rangel, A. R. Silva, and B. SotoBlanco, "Efeitos do gossipol na reprodução animal," Acta Veterinaria Brasilica, vol. 5, no. 2, pp. 129-135, 2011.

[2] I. C. N. Gadelha, N. B. S. Fonseca, S. C. S. Oloris, and B. Soto-Blanco, "Gossypol toxicity from cottonseed products," The Science World Journal, vol. 2014, Article ID 231635, 11 pages, 2014.

[3] D. P. Deoras, P. Young-Curtis, R. R. Dalvi, and F. E. Tippett, "Effect of gossypol on hepatic and serum $\gamma$-glutamyltransferase activity in rats," Veterinary Research Communications, vol. 21, no. 5, pp. 317-323, 1997.

[4] N. B. D. S. Fonseca, I. C. N. Gadelha, S. C. S. Oloris, and B. Soto-Blanco, "Effectiveness of albumin-conjugated gossypol as an immunogen to prevent gossypol-associated acute hepatotoxicity in rats," Food and Chemical Toxicology, vol. 56, pp. 149-153, 2013.

[5] W. Xu, L. Xu, H. Lu et al., "The immunosuppressive effect of gossypol in mice is mediated by inhibition of lymphocyte proliferation and by induction of cell apoptosis," Acta Pharmacologica Sinica, vol. 30, no. 5, pp. 597-604, 2009.

[6] A. P. Braga, M. V. MacIel, D. G. F. Guerra, I. S. A. S. Maia, S. C. S. Oloris, and B. Soto-Blanco, "Extruded-expelled cottonseed meal decreases lymphocyte counts in male sheep," Revue de Medecine Veterinaire, vol. 163, no. 3, pp. 147-152, 2012.

[7] B. Song, G. Huang, C. Tong et al., "Gossypol suppresses mouse T lymphocytes via inhibition of NF $\kappa \mathrm{B}$, NFAT and AP-1 pathways," Immunopharmacology and Immunotoxicology, vol. 35, no. 5, pp. 615-621, 2013.

[8] J. Alexander, D. Benford, A. Cockburn et al., "Gossypol as undesirable substance in animal feed," EFSA Journal, vol. 908, pp. 1-55, 2008.

[9] O. B. Akinola, O. O. Dosunmu, L. Dini, and S. Ajayi, "Proteinaceous diet inhibits gossypol-induced spermatotoxicity," European Journal of Histochemistry, vol. 50, no. 3, pp. 205-208, 2006.

[10] T. A. Taha, W. F. Shaaban, A. R. El-Mahdy, F. D. El-Nouty, and M. H. Salem, "Reproductive toxicological effects of gossypol on male rabbits: semen characteristics and hormonal levels," Animal Science, vol. 82, no. 2, pp. 259-269, 2006.

[11] S. Roychoudhury, P. Massanyi, J. Slamecka et al., "In vitro gossypol induced spermatozoa motility alterations in rabbits," Journal of Environmental Science and Health B, vol. 44, no. 7, pp. 730-741, 2009.

[12] A. S. El-Sharaky, A. A. Newairy, N. M. Elguindy, and A. A. Elwafa, "Spermatotoxicity, biochemical changes and histological alteration induced by gossypol in testicular and hepatic tissues of male rats," Food and Chemical Toxicology, vol. 48, no. 12, pp. 3354-3361, 2010.

[13] Y. Anna, A. G. Medentsev, and V. I. Krupyanko, "Gossypol inhibits electron transport and stimulates ROS generation in yarrowia lipolytica mitochondria," Open Biochemistry Journal, vol. 6, pp. 11-15, 2012.

[14] H. Breitbart, S. Rubinstein, and L. Nass-Arden, "Effect of gossypol-acetic acid on calcium transport and ATPase activity in plasma membranes from ram and bull spermatozoa," International Journal of Andrology, vol. 7, no. 5, pp. 439-447, 1984.

[15] P. J. Chenoweth, C. C. Chase Jr., C. A. Risco, and R. E. Larsen, "Characterization of gossypol-induced sperm abnormalities in bulls," Theriogenology, vol. 53, no. 5, pp. 1193-1203, 2000.

[16] G. S. Romualdo, G. R. Klinefelter, and W. De Grava Kempinas, "Postweaning exposure to gossypol results in epididymisspecific effects throughout puberty and adulthood in rats," Journal of Andrology, vol. 23, no. 2, pp. 220-228, 2002.

[17] M. Zhang, H. Yuan, Z. He et al., "DNA damage and decrease of cellular oxidase activity in piglet sertoli cells exposed to gossypol," African Journal of Biotechnology, vol. 10, no. 14, pp. 2797-2802, 2011.

[18] N. Timurkaan, F. Yilmaz, and S. Timurkaan, "Effects of cottonseed flour on immunohistochemical localization of androgen receptors (AR) in rat testes," Revue de Medecine Veterinaire, vol. 162, no. 1, pp. 13-17, 2011.

[19] M. E. Hassan, G. W. Smith, R. S. Ott et al., "Reversibility of the reproductive toxicity of gossypol in peripubertal bulls," Theriogenology, vol. 61, no. 6, pp. 1171-1179, 2004.

[20] R. K. Lagerlof and J. N. Tone, "The effect of gossypol acetic acid on female reproduction," Drug and Chemical Toxicology, vol. 8, no. 6, pp. 469-482, 1985.

[21] Y. C. Lin, T. Fukaya, Y. Rikihisa, and A. Walton, "Gossypol in female fertility control: ovum implantation and early pregnancy inhibited in rats," Life Sciences, vol. 37, no. 1, pp. 39-47, 1985.

[22] G. Basini, S. Bussolati, L. Baioni, and F. Grasselli, "Gossypol, a polyphenolic aldehyde from cotton plant, interferes with swine granulosa cell function," Domestic Animal Endocrinology, vol. 37, no. 1, pp. 30-36, 2009.

[23] Y. Gu, Y. C. Lin, and Y. Rikihisa, "Inhibitory effect of gossypol on steroidogenic pathways in cultured bovine luteal cells," Biochemical and Biophysical Research Communications, vol. 169, no. 2, pp. 455-461, 1990.

[24] Y. C. Lin, S. Coskun, and A. Sanbuissho, "Effects of gossypol on in vitro bovine oocyte maturation and steroidogenesis in bovine granulosa cells," Theriogenology, vol. 41, no. 8, pp. 16011611, 1994.

[25] F. K. Marcondes, F. J. Bianchi, and A. P. Tanno, "Determination of the estrous cycle phases of rats: some helpful considerations," Brazilian Journal of Biology, vol. 62, no. 4A, pp. 609-614, 2002.

[26] T. Pedersen and H. Peters, "Proposal for a classification of oocytes and follicles in the mouse ovary," Journal of Reproduction and Fertility, vol. 17, no. 3, pp. 555-557, 1968.

[27] T. Israely, H. Dafni, D. Granot, N. Nevo, A. Tsafriri, and M. Neeman, "Vascular remodeling and angiogenesis in ectopic ovarian transplants: a crucial role of pericytes and vascular smooth muscle cells in maintenance of ovarian grafts," Biology of Reproduction, vol. 68, no. 6, pp. 2055-2064, 2003.

[28] A. Camboni, B. Martinez-Madrid, M. Dolmans, G. Macchiarelli, J. Donnez, and S. A. Nottola, "Contribution of transmission electron microscopy to the study of human ovarian tissue integrity after enzymatic isolation, cryopreservation or xenografting," Fertility and Sterility, vol. 84, supplement 1, p. S104, 2005.

[29] H. S. Bender, G. K. Saunders, and H. P. Misra, "A histopathologic study of the effects of gossypol on the female rat," Contraception, vol. 38, no. 5, pp. 585-592, 1988.

[30] Y. Gu and N. O. Anderson, "Effects of gossypol on the estrous cycle and ovarian weight in the rat," Contraception, vol. 32, no. 5, pp. 491-496, 1985. 
[31] D. W. Hahn, C. Rusticus, A. Probst, R. Homm, and A. N. Johnson, "Antifertility and endocrine activities of gossypol in rodents," Contraception, vol. 24, no. 1, pp. 97-105, 1981.

[32] Y.-M. Wu, S. C. Chappel, and G. L. Flickinger, "Effects of gossypol on pituitary-ovarian endocrine function, ovulation and fertility in female hamsters," Contraception, vol. 24, no. 3, pp. 259-268, 1981.

[33] Y. Q. Yang and X. Y. Wu, "Antifertility mechanisms of gossypol acetic acid in female rats," Journal of Reproduction and Fertility, vol. 80, no. 2, pp. 425-429, 1987.

[34] W. Nai-Gong, G. Mu-Zhen, and L. Hai-Peng, "Effects of gossypol acetic acid on rat luteal cells in vitro," Journal of Ethnopharmacology, vol. 20, no. 1, pp. 45-51, 1987.

[35] J. Vranová, M. Ježová, S. Scsuková, and J. Kolena, “Inhibitory effect of gossypol on basal and luteinization factor-stimulated progesterone synthesis in porcine granulosa cells," Physiological Research, vol. 48, no. 2, pp. 119-128, 1999.

[36] J. Kolena, S. Vršanská, E. Nagyová, and M. Ježová, “Gossypol inhibits follicle-stimulating hormone- and epidermal growth factor-stimulated expansion of oocyte-cumulus complexes from porcine preovulatory follicles," Physiological Research, vol. 50, no. 6, pp. 627-630, 2001.

[37] Y. Gu, C. J. G. Chang, Y. Rikihisa, and Y. C. Lin, "Inhibitory effect of gossypol on human chorionic gonadotropin (hCG)induced progesterone secretion in cultured bovine luteal cells," Life Sciences, vol. 47, no. 5, pp. 407-414, 1990.

[38] Y. Rikihisa and Y. C. Lin, "Effect of gossypol on the thyroid in young rats," Journal of Comparative Pathology, vol. 100, no. 4, pp. 411-417, 1989.

[39] Y. C. Lin, M. Chitcharoenthum, and Y. Rikihisa, "Effect of gossypol on thyroid hormones in young female rats," Contraception, vol. 41, no. 4, pp. 431-440, 1990.

[40] F. Tang and P. Y. D. Wong, "Serum potassium and aldosterone levels in gossypol-treated rats," International Journal of Andrology, vol. 7, no. 2, pp. 149-153, 1984.

[41] M. Y. El-Mokadem, T. A. Taha, M. A. Samak, and A. M. Yassen, "Alleviation of reproductive toxicity of gossypol using selenium supplementation in rams," Journal of Animal Science, vol. 90, no. 9, pp. 3274-3285, 2012.

[42] P. Udoh, D. R. Patil, and M. K. Deshpande, "Histopathological and biochemical effects of gossypol acetate on pituitary-gonadal axis of male albino rats," Contraception, vol. 45, no. 5, pp. 493509, 1992.

[43] A. N. Hirshfield, "Overview of ovarian follicular development: considerations for the toxicologist," Environmental and Molecular Mutagenesis, vol. 29, no. 1, pp. 10-15, 1997.

[44] H. Atmaca, G. Gorumlu, B. Karaca et al., "Combined gossypol and zoledronic acid treatment results in synergistic induction of cell death and regulates angiogenic molecules in ovarian cancer cells," European Cytokine Network, vol. 20, no. 3, pp. 121-130, 2009.

[45] J. Wang, L. Jin, X. Li et al., "Gossypol induces apoptosis in ovarian cancer cells through oxidative stress," Molecular BioSystems, vol. 9, no. 6, pp. 1489-1497, 2013. 

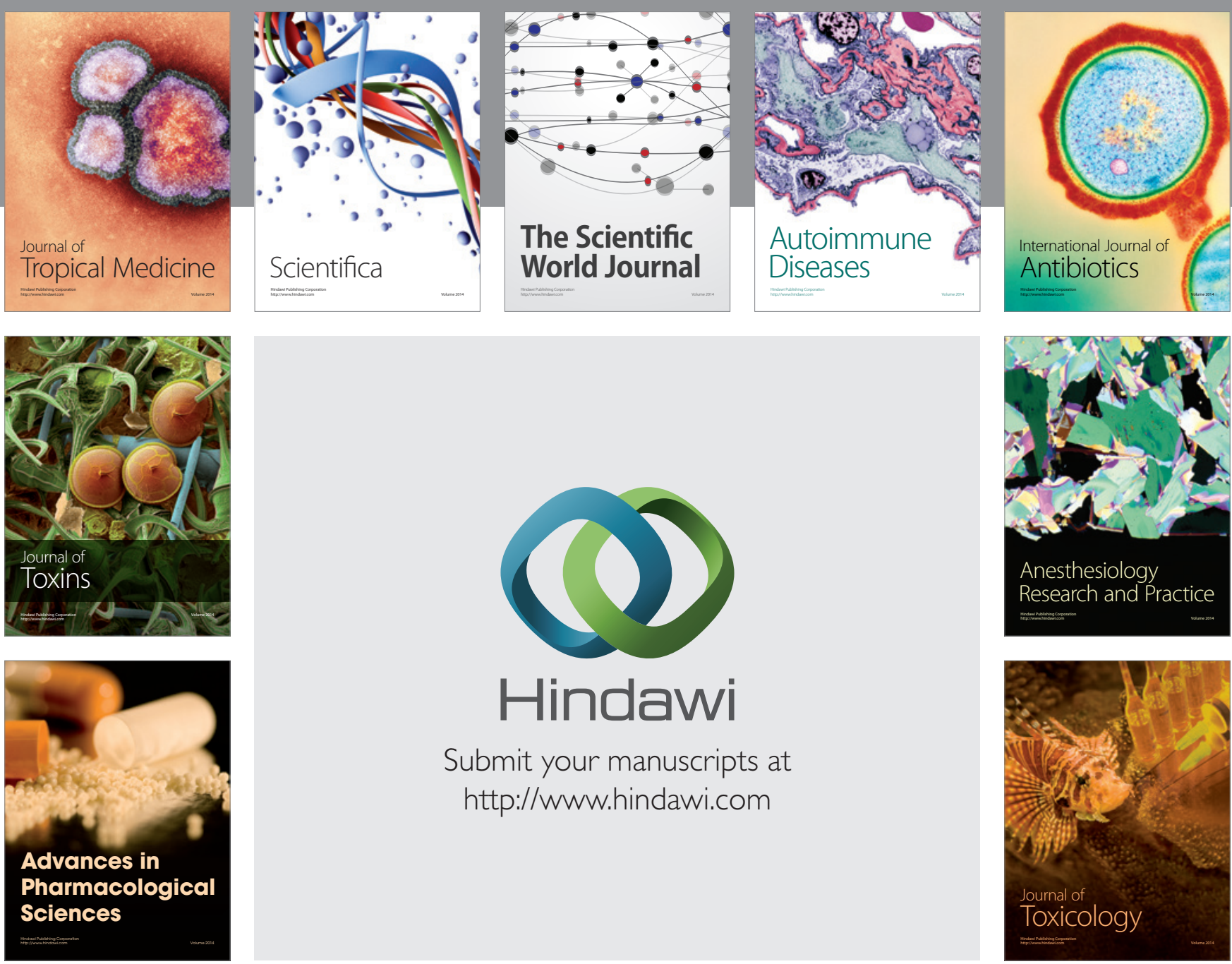

\section{Hindawi}

Submit your manuscripts at

http://www.hindawi.com
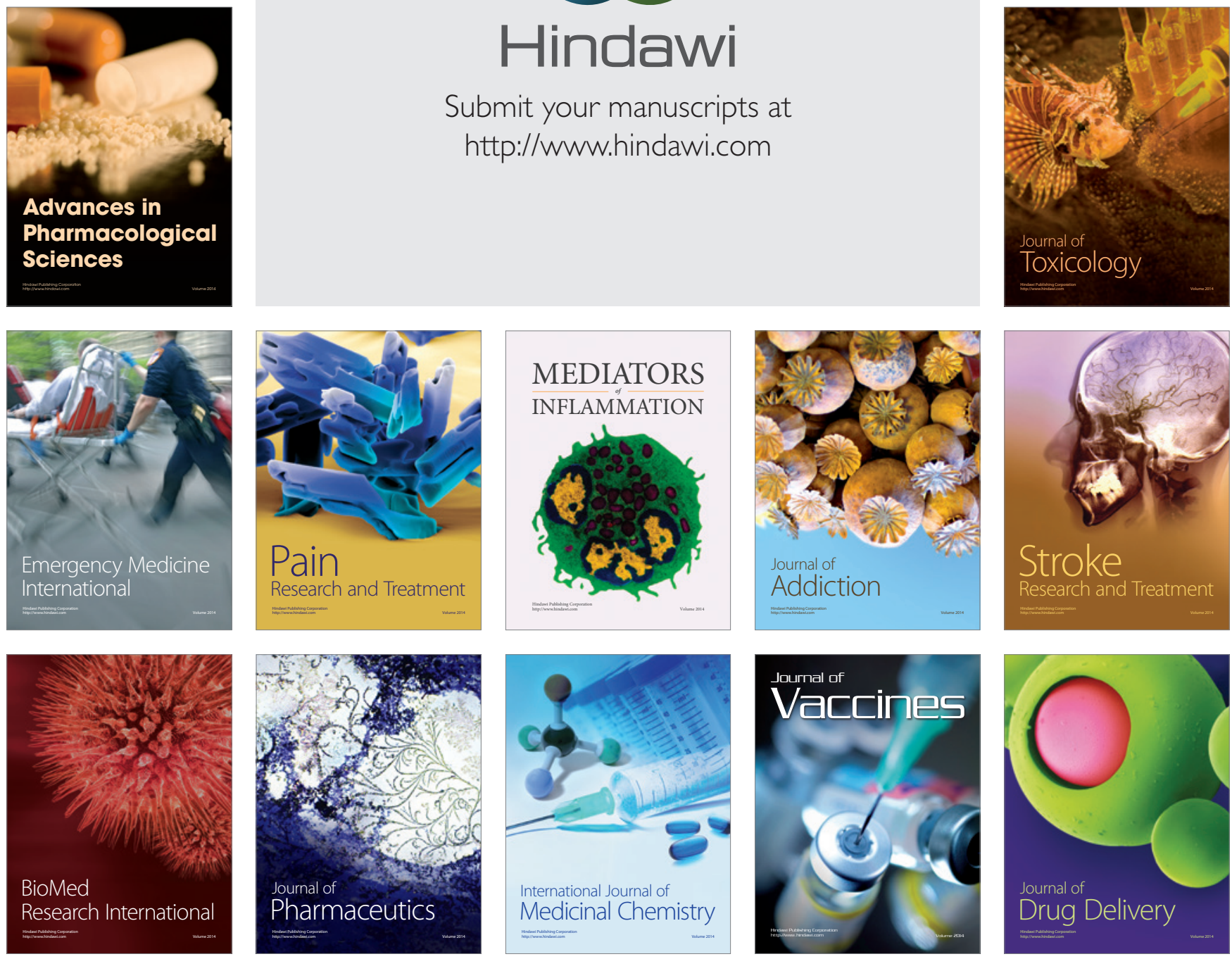